\title{
Empathizing, Systemizing, and Autistic Traits: Latent Structure in Individuals With Autism, Their Parents, and General Population Controls
}

\author{
Rachel Grove and Andrew Baillie \\ Macquarie University
}

\author{
Carrie Allison and Simon Baron-Cohen \\ Cambridge University
}

\author{
Rosa A. Hoekstra \\ Cambridge University and The Open University
}

\begin{abstract}
The search for genes involved in autism spectrum conditions (ASC) may have been hindered by the assumption that the different symptoms that define the condition can be attributed to the same causal mechanism. Instead the social and nonsocial aspects of ASC may have distinct causes at genetic, cognitive, and neural levels. It has been posited that the core features of ASC can be explained by a deficit in empathizing alongside intact or superior systemizing; the drive to understand and derive rules about a system. First-degree relatives also show some mild manifestations that parallel the defining features of ASC, termed the broader autism phenotype. Factor analyses were conducted to assess whether the latent structure of empathizing, systemizing, and autistic traits differs across samples with a high (individuals on the spectrum), medium (first-degree relatives) or low (general population controls) genetic vulnerability to autism. Results highlighted a two-factor model, confirming an empathizing and a systemizing factor. The relationship between these two factors was significantly stronger in first-degree relatives and the autism group compared with controls. The same model provided the best fit among the three groups, suggesting a similar latent structure irrespective of genetic vulnerability. However, results also suggest that although these traits are relatively independent in the general population, they are substantially correlated in individuals with ASC and their parents. This implies that there is substantially more overlap between systemizing and empathizing among individuals with an increased genetic liability to autism. This has potential implications for the genetic, environmental, and cognitive explanations of autism spectrum conditions.
\end{abstract}

Keywords: autism, factor analysis, genetics, broader autism phenotype, family studies

Autism spectrum conditions (ASC) are characterized by impairment in the development of communication skills and reciprocal social interaction alongside the presence of unusually repetitive behaviors and narrow interests (Diagnostic and Statistical Manual of Mental Disorders, fourth edition, revised [DSM-IV-TR]; American Psychiatric Association, 2000). It is well established through family and twin studies that these conditions have a strong genetic

Rachel Grove and Andrew Baillie, Centre for Emotional Health, Department of Psychology, Macquarie University, Sydney, NSW, Australia; Carrie Allison and Simon Baron-Cohen, Autism Research Centre, Department of Psychiatry, Cambridge University, Cambridge, United Kingdom; Rosa A. Hoekstra, Autism Research Centre, Department of Psychiatry, Cambridge University, Cambridge, United Kingdom and Faculty of Science, The Open University, Milton Keynes, United Kingdom.

We thank the individuals who participated in the study. We acknowledge support from the Medical Research Council (U.K.; program grant to S.B.C.). This work was conducted in association with the NIHR CLAHRC for Cambridgeshire and Peterborough NHS Foundation Trust. R.G. was supported by a National Health and Medical Research Council (Australia) Postgraduate Scholarship (\#1017041).

Correspondence concerning this article should be addressed to Rachel Grove, Centre for Emotional Health, Department of Psychology, Macquarie University, NSW 2109 Australia. E-mail: rachel.grove@mq.edu.au component. A range of twin studies have indicated substantially higher concordance rates for clinical autism in monozygotic twins when compared with dizygotic twins. Altogether, these findings indicate strong genetic influences on ASC with a heritability estimate of around 80\%, (Ronald \& Hoekstra, 2011). A recent large scale family study suggests the recurrence rate for autism within families is close to $20 \%$ (Ozonoff et al., 2011). This, coupled with prevalence estimates of around $1 \%$ (Baron-Cohen et al., 2009; Brugha et al., 2011), suggests a markedly increased risk for autism within families, highlighting a strong influence of genetic effects. There is also a growing body of evidence from molecular genetic studies suggesting the involvement of multiple genetic variants and loci in the development of these conditions (Abrahams \& Geschwind, 2008; Geschwind, 2011).

There is evidence to suggest that family members show mild manifestations that parallel the defining features of autism, a phenomenon termed the Broader Autism Phenotype (BAP; see Sucksmith, Roth, \& Hoekstra, 2011 for a review). With the development of quantitative psychometric instruments such as the Autism Spectrum Quotient (AQ; Baron-Cohen, Wheelwright, Skinner, Martin, \& Clubley, 2001), that assess autistic traits on a continuous scale, it is now possible to measure these subthreshold autistic traits with more precision. Use of such scales in family studies may provide insights into the genetic factors involved in ASC and the familial risk for developing autism. 
A multitude of studies have reported mild impairments in relatives of individuals with autism, particularly in the social and communicative domains. For example, parents of individuals with ASC have been shown to display more social and communication difficulties, as measured by subscales of the AQ, as well as score lower on measures of pragmatics (Piven, Palma, et al., 1997; Ruser et al., 2007). Siblings also show difficulties in reciprocal social interaction (Nadig et al., 2007; Toth, Dawson, Meltzoff, Greenson, $\&$ Fein, 2007). Similarly, parents show some mild difficulties with social cognition, as measured by neuropsychological tests (Losh et al., 2009; Losh \& Piven, 2007). Parents of children with an ASC also perform lower than a control group on a task assessing the ability to read complex emotional states from viewing the eye region of the face (Baron-Cohen \& Hammer, 1997; Losh \& Piven, 2007), providing evidence for the BAP at a cognitive level.

Although the evidence for some of the nonsocial aspects of ASC among relatives is more modest, a number of studies suggest an elevated rate of stereotyped behaviors and circumscribed hobbies in parents (Bolton et al., 1994; Briskman, Happe, \& Frith, 2001; Piven, Palmer, Jacobi, Childress, \& Arndt, 1997). Some studies suggest that first degree relatives of individuals with ASC may also display the same "cognitive style" that leads to superior performance on tasks where visual processing of local material is advantageous, including the Embedded Figures Task (BaronCohen \& Hammer, 1997; Bölte \& Poustka, 2006; Happé, Briskman, \& Frith, 2001) and the Block Design Task (Scheeren \& Stauder, 2008). However, findings related to tasks assessing local processing styles have been somewhat inconsistent, both in clinical groups (White \& Saldaña, 2011) and in first degree relatives (see Sucksmith et al., 2011 for a review).

There has been much debate around whether the triad of features characteristic of autism (social impairments, communication impairments and repetitive behavior/narrow interests) are influenced by the same genetic and environmental factors, or whether they are somewhat independent. Happé and Ronald (2008) suggest that the core features that define autism are largely "fractionable"; that is, that they may have distinct causes at genetic, cognitive, and neural levels. There are a number of family and twin studies that support this notion, showing that although the three sets of features are highly heritable individually, they are affected by largely independent genetic influences (Ronald, Happé, Bolton, et al., 2006; Ronald, Happé, \& Plomin, 2005; Ronald, Happé, Price, BaronCohen, \& Plomin, 2006). Moreover, $10 \%$ of children in a large general population study showed only social impairment, only communication difficulties, or only repetitive and restricted interests (Ronald, 2006), suggesting these characteristics can also occur in isolation.

Similarly, a review of factor analytic studies showed that, of the seven studies included, six found evidence for multiple factors underlying autistic features (Mandy \& Skuse, 2008). Although the total number of factors identified varied across studies, all studies (see Constantino et al., 2004 for an exception) reported at least one social-communication factor and all but one also reported at least one distinct nonsocial factor (Mandy \& Skuse, 2008). Taken together, these studies suggest that partially distinct causal explanations should be sought for the social and nonsocial aspects of ASC.

This hypothesis has so far mainly focused on features at a behavioral level. However, there are a number of theoretical ex- planations that attempt to account for the features in autism at the cognitive level. It has been suggested that these conditions are associated with difficulties in executive function (Corbett, Constantine, Hendren, Rocke, \& Ozonoff, 2009; Ozonoff, Pennington, \& Rogers, 1991; Russell, 1997), 'weak central coherence' (a processing bias in which individuals focus on the local rather than global features of an object), and "Theory of Mind" (the ability to attribute mental states to oneself and others) (Baron-Cohen, Leslie, \& Frith, 1985).

The term "empathizing" extends the idea of Theory of Mind and involves two components: the ability to attribute mental states to oneself and others and the drive to respond with an appropriate emotion to that mental state (Baron-Cohen, 2004, 2010). A different process, systemizing, is conceptualized as the drive to understand and derive rules about a system (Baron-Cohen, 2002). Systemizing allows an individual to predict the behavior of a system and therefore to control it (Baron-Cohen, 2010). A system is defined as anything that takes inputs and delivers outputs, and includes everything from technical systems (e.g., a machine) through to natural (e.g., the weather), abstract (e.g., mathematics), social (e.g., a company), collectible (e.g., a library), and motoric (e.g., a tennis top-spin) systems that the brain can analyze or construct (Baron-Cohen, 2004)

According to the Empathizing-Systemizing (E-S) theory, autism is best explained by a deficit in empathy alongside intact or even superior systemizing (Baron-Cohen, 2004, 2010; Baron-Cohen, Knickmeyer, \& Belmonte, 2005; Baron-Cohen, Wheelwright, Lawson, Griffin, \& Hill, 2002). In this way, the social and communication impairments seen in these conditions can be accounted for by empathising, and the islets of ability, repetitive behavior, and restricted interests or obsessions with systems can be accounted for by an interest in systemizing (Baron-Cohen, 2004, 2010). There is a large evidence base suggesting that individuals with ASC show impaired performance on measures of empathizing and intact or elevated performance on tests of systemizing ability (Baron-Cohen, Richler, Bisarya, Gurunathan, \& Wheelwright, 2003; Baron-Cohen \& Wheelwright, 2004; Baron-Cohen, Wheelwright, \& Jolliffe, 1997; Baron-Cohen, Wheelwright, Stone, \& Rutherford, 1999; Jolliffe \& Baron-Cohen, 1997; Lai et al., 2011; Lawson, BaronCohen, \& Wheelwright, 2004).

As yet it remains unclear the extent to which empathizing and systemizing traits are related. Given that people with ASC tend to perform poorly on tasks of empathizing and do well on tasks of systemizing, an inverse correlation between the two traits would be expected in this group, provided that these traits are assessed on continuous scales that allow for sufficient variance within the clinical group. However, it is less clear whether this inverse association is linear across populations and would also apply to nonclinical samples. The current study aims to assess the association between empathizing, systemizing, and social and nonsocial autistic traits across three distinct samples, stratified by their genetic risk for autism. This study reports on factor analyses employed in three distinct samples comprising individuals with a clinical ASC diagnosis (high genetic vulnerability), parents of a child with ASC (medium genetic risk), and a general population control group (low genetic vulnerability). 


\section{Method}

\section{Participants}

Individuals with a clinical ASC diagnosis and parents of a child with ASC were recruited via the participant database at the Autism Research Centre at the University of Cambridge (www.autismresearchcenter.com). To account for any potential response bias, the control sample was collected via a different portal at a general (nonclinical) volunteer psychology research webpage (www.cambridgepsychology.com). Participants were included in the study if they were 18 years and over and had completed all measures. The individuals in the ASC group and the children of the parent group were reported to all have received a formal ASC diagnosis from experienced clinicians in recognized clinics.

Individuals in the parent group did not report having an ASC diagnosis themselves. The control group was confined to individuals who did not report any past psychiatric history. The total sample consisted of 1034 individuals, comprising 363 individuals with ASC $($ males $=193$, females $=170$, mean age $=36$ years, $\mathrm{SD}=11), 439$ parents of a child with ASC (males $=141$, females $=298$, mean age $=42$ years, $\mathrm{SD}=8$ ), and 232 controls ( males $=122$, females $=$ 110 , mean age $=33$ years, $\mathrm{SD}=10) .79 .9 \%$ of the control group had completed higher education, whereas $49.9 \%$ of the parent group and $54.0 \%$ of individuals with ASC had completed an undergraduate degree.

\section{Measures}

Individuals registered in either of the above websites were asked to fill out a range of well-validated questionnaires assessing empathizing, systemizing, and quantitative autistic traits. Participants were able to complete the questionnaires in their preferred order. The measures used are designed as dimensional quantitative measures of empathizing, systemizing, and autistic traits, in keeping with the paradigm that autism is best represented along a spectrum of symptoms. As these measures are not designed as clinical instruments this allows for variance across the three sample groups.

Empathizing and systemizing. The Empathy Quotient (EQ; Baron-Cohen \& Wheelwright, 2004) is a self-report measure of empathizing. Items assess the ability to attribute mental states to oneself and others and the drive to respond with an appropriate emotion to that mental state. An example of an item assessing recognizing the mental state of another is 'I am quick to spot when someone in a group is feeling awkward or uncomfortable.' 'I tend to get emotionally involved with a friend's problems' is an example of an item assessing the drive to respond emotionally to another's mental state. The EQ is comprised of 40 statements scored on a Likert scale including four response options: definitely disagree, slightly disagree, slightly agree, and definitely agree. For approximately half the items an "agree" response is in line with high empathy abilities. On these items "definitely agree" responses score two points and "slightly agree" responses score one point, with "definitely disagree" and "slightly disagree" scoring zero. The other half of the items are reverse-scored, as a "disagree" response refers to better empathizing on these items. Scores range from zero to 80 and follow a near normal distribution, with a higher score reflecting increased empathizing ability. Adults with high functioning autism or Asperger's syndrome have been shown to score significantly lower on the EQ than age-matched controls (Baron-Cohen \& Wheelwright, 2004).

The Systemizing Quotient-Revised (SQ-R; Wheelwright et al., 2006) is a self-report measure of systemizing consisting of 75 statements with four response options: strongly agree, slightly agree, slightly disagree, and strongly disagree. Scoring procedures are equivalent to those described for the EQ. Scores follow a continuous distribution ranging from zero to 150 , with higher scores reflecting stronger systemizing behavior. Items include statements like 'When I learn about a new category I like to go into detail to understand the small differences between different members of that category,' and 'In math, I am intrigued by the rules and patterns governing numbers.' Individuals with autism score higher on the SQ-R compared with age-matched controls (Baron-Cohen et al., 2003; Goldenfeld, Baron-Cohen, \& Wheelwright, 2005; Goldenfeld, Baron-Cohen, Wheelwright, Ashwin, \& Chakrabarti, 2007; Lai et al., 2011; Wheelwright et al., 2006).

Autistic traits. The Autism Spectrum Quotient (AQ; BaronCohen et al., 2001) is a self-report quantitative measure of autistic traits. The AQ consists of 50 items assessing the core areas of difficulty in ASC including impaired social skills, communication difficulties, imagination and attention switching and a superior attention to detail. Participants were asked to rate themselves on a 4-point Likert scale with response categories definitely disagree, slightly disagree, slightly agree, and definitely agree. This study used the raw scoring method (as detailed in Hoekstra, Bartels, Cath, \& Boomsma, 2008), with total scores following a normal distribution ranging from 50 to 200 and a score of 200 representing full endorsement of all autistic traits. Individuals with an ASC show significantly higher scores on the AQ compared with the general population (Baron-Cohen et al., 2001).

Recent evidence suggests that the AQ can be split into two categories of items, reflecting a broad social interaction factor comprising the social skills, attention switching, communication and imagination items and an attention to detail factor (Hoekstra et al., 2008). These two factors only correlate modestly and are therefore useful in making the distinction between social and nonsocial autistic traits (Hoekstra et al., 2008). The AQ was split into these two subscales for the current analysis.

\section{Analytic Strategy}

There is a large evidence base suggesting that scores on the measures included in this study are affected by sex (Baron-Cohen et al., 2005; Baron-Cohen et al., 2011). The main focus of this study was on the factor structure, not on sex differences in mean scores, which have been studied for our measures of interest in previous studies (see, e.g., Baron-Cohen et al., 2001; Hoekstra et al., 2008; Sucksmith, Allison, Baron-Cohen, Chakrabarti, \& Hoekstra, 2013; Wheelwright et al., 2006). To account for the effects of sex as well as the potential confounding effect of age on the means, variables were standardized via regression analyses in SPSS for age and sex before analysis.

After standardization, a series of confirmatory factor (CFA) models were specified and estimated in MPlus version 6.11 (Muthén \& Muthén, 2010a) using the maximum likelihood estimator (Muthén \& Muthén, 2010b). A one-factor model encompassing all measures of empathizing, systemizing, and autistic 
traits was fit for each of the three groups separately (Models 1-3). After this a two-factor model was fit across the three groups (Models 4-6). The EQ and the social interaction subscale of the AQ (AQ_soc) were predicted to load on one latent "empathizing" factor, whereas the scores on the SQ-R and the attention to detail factor (AQ_att) were expected to load on a "systemizing" factor. Scores on the social interaction subscale of the AQ (AQ_soc) were reverse scored to enable ease of interpretation. Empathizing ability is therefore indicated by high scores on the EQ and high scores on the social interaction subscale of the AQ, whereas systemizing ability is indicated by high scores on the SQ and on the attention to detail factor of the AQ.

To assess the full range of models available, and to test whether our hypothesized Empathizing-Systemizing model (tested in Models 4-6) provided the best fit, two further models were specified, the first including the SQ-R and the social subscale of the AQ (AQ_soc) on one factor, with the EQ and the attention to detail factor (AQ_att) loading on a second factor (Models 7-9). The second model included the EQ and SQ-R on the first factor and both sections of the AQ loading on a second factor (Models 10-12). Both models were fit across the three groups.

Models 1 to 12 were fit within the three individual groups to allow for a different factor structure relative to genetic liability. However, it is important to evaluate the equivalence of the parameters estimated in a CFA across groups (Brown, 2006). This can be achieved within one model using multigroup CFA. Multiple group models make it possible to pinpoint where any specific differences across groups may fall (Brown, 2006). Therefore, to assess whether these traits function differently among the three groups, a further model was implemented, allowing all parameter estimates to vary (Model 13). A further model in which the factor loadings were constrained to be equal across groups was also implemented (Model 14).

To test whether the same factor structure was identified for males and females within each sample group, a further three models were tested, with varying restrictions, across six groups split by sex and genetic vulnerability. Model 15 contains a multigroup CFA allowing all estimates to vary across the six groups. A second model was fit constraining the factor loadings to be equal (Model 16). A final model restricted the factor correlations to be equal for males and females as well as equal factor loadings across the six groups (Model 17).

Model fit was evaluated using the following goodness of fit statistics; Akaike information criterion (AIC; Akaike, 1987), Bayesian information criterion (BIC; Schwarz, 1978), Sample size adjusted BIC (SSABIC; Sclove, 1987), Root mean square error of approximation (RMSEA; Steiger \& Lind, 1980), Comparative fit index (CFI; Bentler, 1987), and Tucker-Lewis index (TLI; Tucker \& Lewis, 1973). The AIC, BIC, and SSABIC are parsimonyadjusted indices used to examine model fit, with lower values indicating a better fit. It has been suggested that a RMSEA value $<0.05$ indicates a close model fit, with values up to 0.08 suggesting a reasonable error of approximation (Browne \& Cudeck, 1993). Current recommendations state that a CFI and TLI value $>=0.90$ indicate acceptable fit with values $>=0.95$ indicative of very good fit to the data (Brown, 2006; Hu \& Bentler, 1999).

As well as taking into account the fit indices mentioned above, evaluation of model fit also took into account the strength and interpretability of the structural parameter estimates.

\section{Results}

Distribution of scores on the subscales of the AQ, the EQ and SQ, standardized for age and sex, are given in Figure 1, showing adequate coverage of the possible range of responses. Model fit indices ascertained from the CFA models are given in Table 1. The one-factor models displayed poor fit among the three groups. In contrast, the two-factor model accounting for measures of systemizing and empathizing provided an excellent fit to the data within all three groups (see Models 4-6). RMSEA values of 0 occur as a result of a chi square value less than the number of degrees of freedom (Kenny, Kaniskan, \& McCoach, 2011). Similarly, CFI and TLI values are also affected by the chi square statistic as well as the degrees of freedom in the model (Brown, 2006). However, these values are indicative of almost perfect model fit (Savalei, 2010). The further two-factor models (Models 7-12) displayed poor fit among the three groups. Models 7 and 10 displayed a correlation greater than 1 between the two factors, indicating that there is no distinction between them. Similarly, fit statistics for Models 8 and 9 fell under the required thresholds, suggesting that the empathizing-systemizing two-factor model (tested in Models 4-6) described the data best in all three groups.

Multiple group analyses were conducted to assess for specific group differences within the two-factor model where the EQ and the social interaction subscale of the AQ (AQ_soc) load on the latent "empathizing" factor, whereas the scores on the SQ-R and the attention to detail factor (AQ_att) load on a "systemizing" factor. Model 13 showed a good fit to the data, with a CFI and TLI above 0.97. Although the RMSEA is larger than the cut-off recommended for model fit, this value is affected by the number of free parameters in the model (Browne \& Cudeck, 1993). Because Model 13 includes more parameters, the RMSEA of this model is relatively high compared with Models 4-6. Furthermore, with limited degrees of freedom the RMSEA value is of less concern given all other indices are strong and suggest a good fit (Brown, 2006). This is the case in Model 13 with CFI and TLI values falling above the specified threshold.

A model in which the factor loadings were constrained to be equal across the three groups (Model 14) resulted in a significantly poorer fit compared to the fit of Model $13\left(\chi^{2}=59.37, p<.001\right)$. Therefore, Model 13, the two-factor model with equal form among the three groups, allowing the factor loadings to vary, provided the best fit to the data. Evaluation of Models 15 to 17 showed that the model constraining the factor correlations to be equal across males and females in each group (Model 17) provided the best fit to the data, indicating that the factor structure obtained in Model 13 does not differ when sex is taken into account.

Factor loadings, correlations, and confidence intervals for the two-factor model taken from the Model 13 analysis are given in Figure 2. All factor loadings were salient and statistically significant $(p<.05)$, reflecting that these measures are good indicators of their respective factors. Parents scored lower on the latent factor mean of empathizing than the control group (Mean Difference $=-0.31, p<.01)$. However, there was no significant difference between scores on the systemizing factor between the parent and control groups. The ASC group showed lower scores on the latent factor empathizing compared with controls (Mean difference $=-2.68, p<.01$ ) and the parent group (Mean difference $=$ $-2.37, p<.01)$ as well as superior latent mean scores on system- 

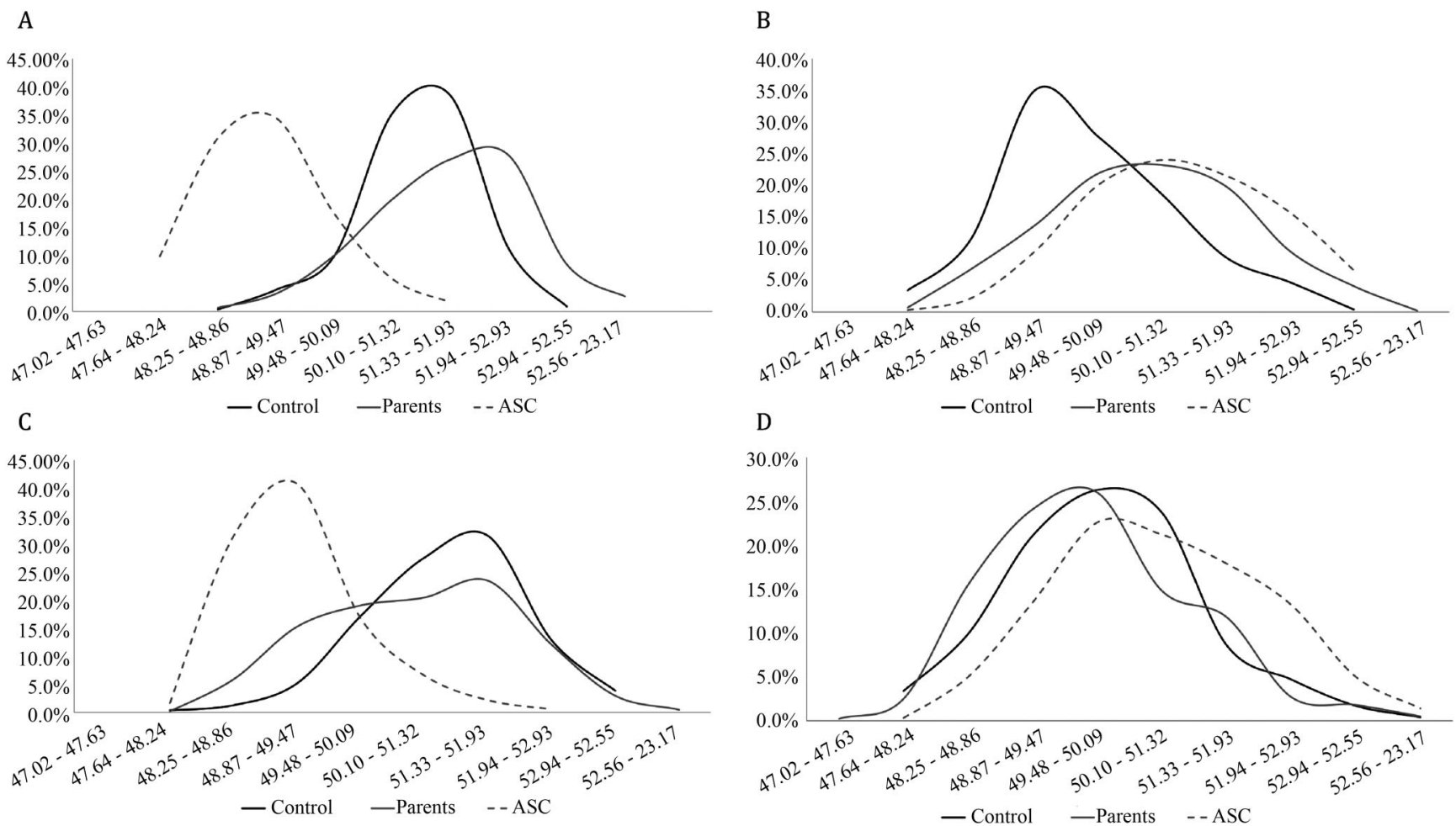

Figure 1. A, Distribution of scores on the social factor of the Autism Spectrum Quotient. B, Distribution of scores on the attention to detail factor of the Autism Spectrum Quotient. C, Distribution of scores on the Empathy Quotient. D, Distribution of scores on the Systemizing Quotient Revised.

izing compared with controls (Mean difference $=1.01, p<.01$ ) and the parent group (Mean difference $=1.14, p<.01$ ).

The correlation between empathizing and systemizing was significant among the three groups. The negative correlation between the two factors was significantly stronger in both the ASC group $(r=-0.61)$ and the parent group $(r=-0.57)$ compared with the control group $(r=-0.22)$. However, the correlations between the two factors for the ASC group and parent group did not differ (i.e., the confidence intervals for the correlations between empathizing and systemizing in the parent and ASC groups overlapped).

\section{Discussion}

The current study examined the structure of autistic characteristics across individuals with a low, medium, and high genetic vulnerability for autism. Results indicated that the two-factor model provided the best fit across the three groups irrespective of sex. This model comprises an empathizing factor including both the EQ and the social behavioral and cognitive traits measured by the $\mathrm{AQ}$, and a systemizing factor including the SQ-R and the "attention to detail" traits measured by the AQ. The latent empathizing factor and systemizing factor were inversely correlated in all three groups. The factor correlations ranged from small to large, providing support for the notion that the social and nonsocial aspects of ASC may have distinct causes at a behavioral level (Happé \& Ronald, 2008; Ronald, 2006; Ronald, Happé, Bolton, et al., 2006; Ronald, Happé, Price, et al., 2006).
Perhaps the most notable finding from the current study is the difference in the strength of the inverse relationship between empathizing and systemizing among controls, first-degree relatives, and individuals on the spectrum. The association between empathizing and systemizing was substantially stronger in individuals with ASC and parents of a child with ASC than in general population controls. Although a definitive explanation for these associations cannot be given without further research, there are a number of potential explanations why these constructs may be more strongly associated in individuals with autism and their first-degree relatives.

First, individuals on the spectrum are given a diagnosis of an ASC. This by definition includes symptoms from all three domains of social impairment, communication difficulties, and repetitive behavior/narrow interests (American Psychiatric Association, 2000). Because systemizing and empathizing are cognitive explanations of autism, individuals with autism are likely to be both superior in systemizing and weaker in empathizing. It is therefore not surprising that these two factors are highly inversely related in this group, given that the presence of all three core symptoms of autism make high systemizing and low empathizing more likely. However, this account does not apply to the parent group as these parents do not have a diagnosis of ASC themselves and are therefore not directly selected to score high on systemizing and low on empathizing.

An alternative explanation for our findings could be that empathizing and systemizing are highly correlated in individuals with ASC due to cognitive strategies used by this group. Because of their poor intuitive empathic abilities, individuals with autism may 
EMPATHIZING, SYSTEMIZING, AND AUTISTIC TRAITS

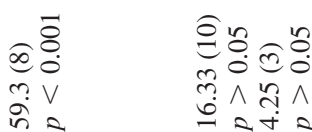

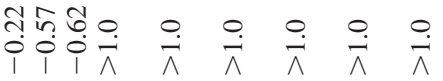

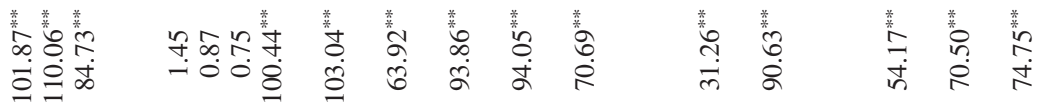

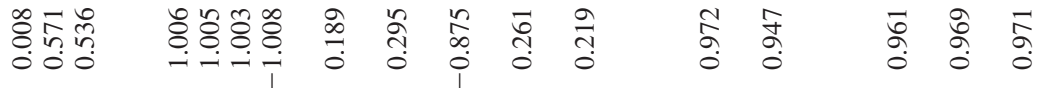

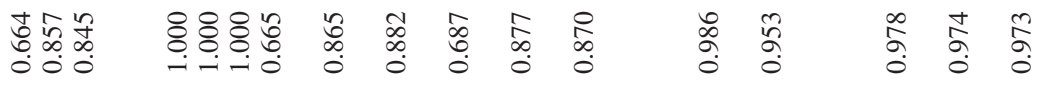

苛留

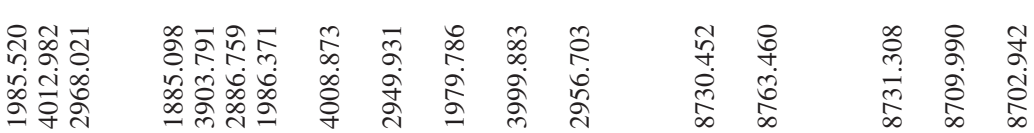

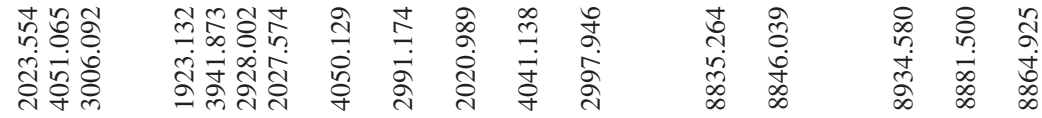

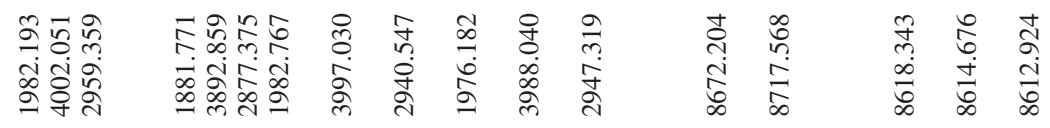

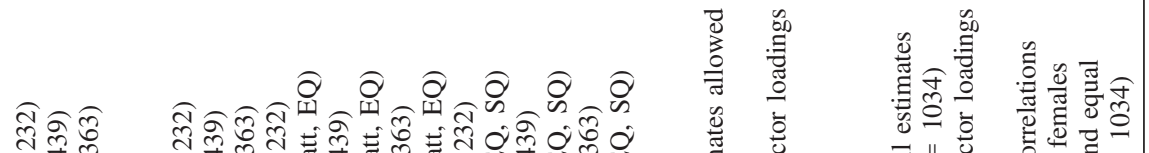

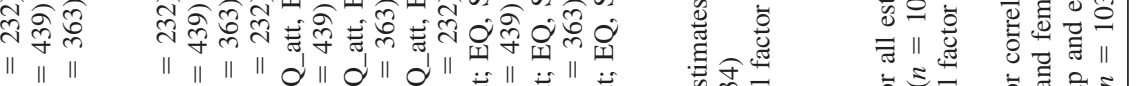

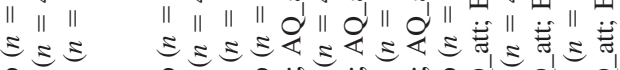

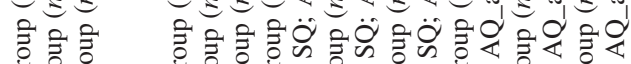

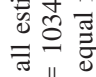

品品

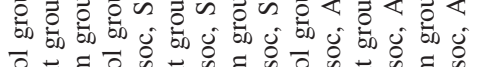

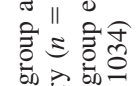

总苾量

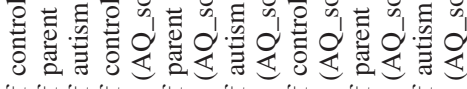

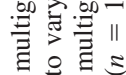

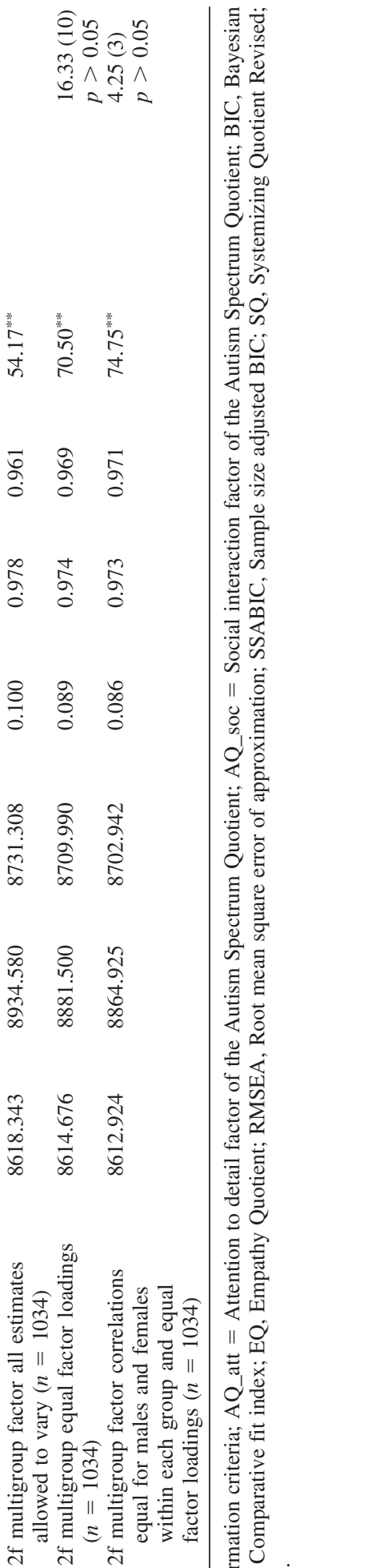

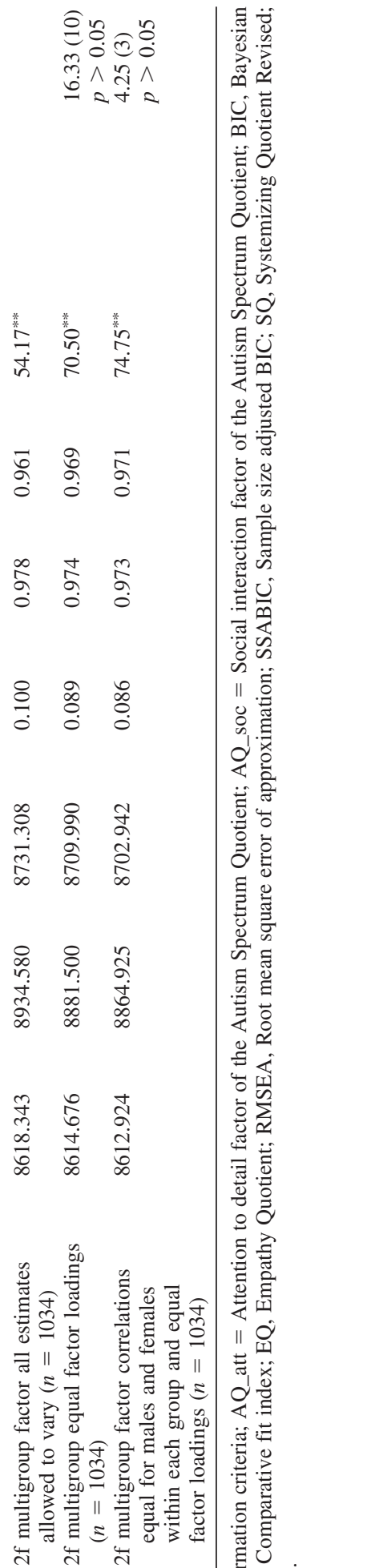

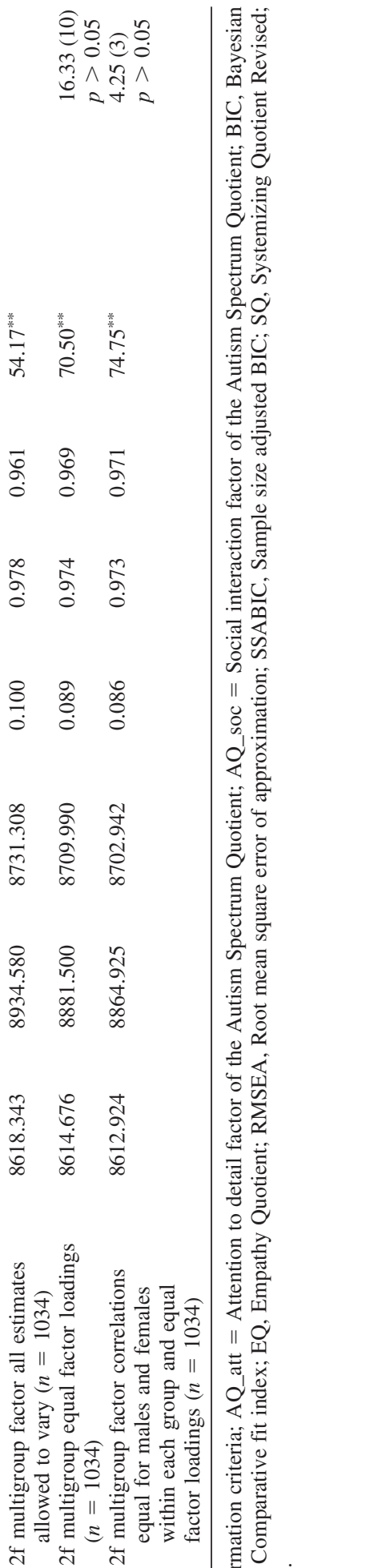

$\pm \pm \pm$

ये

पे

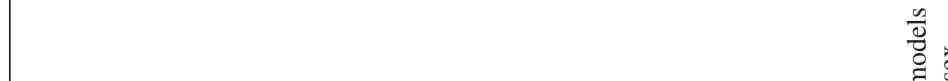

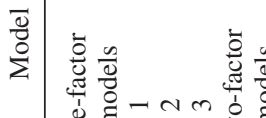

存

总宅造

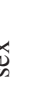

善

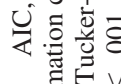

它总当。 
A

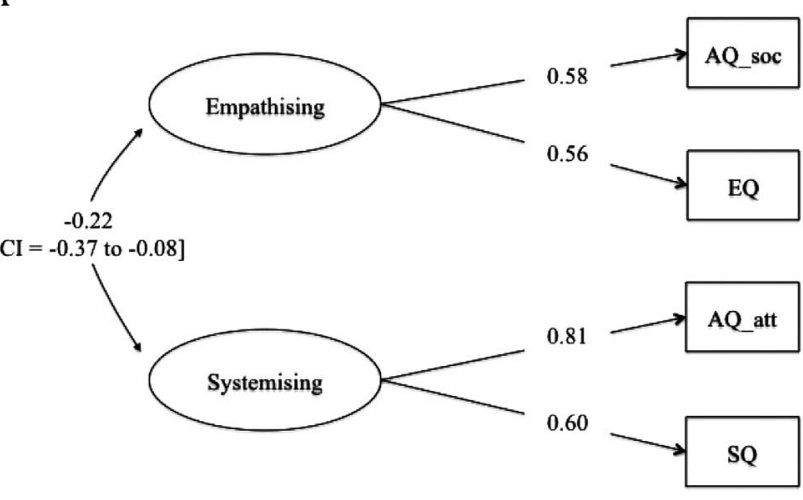

B

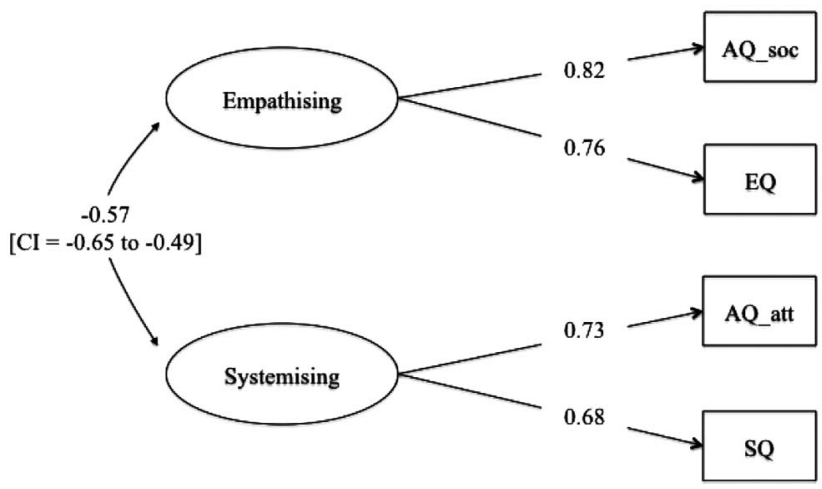

C

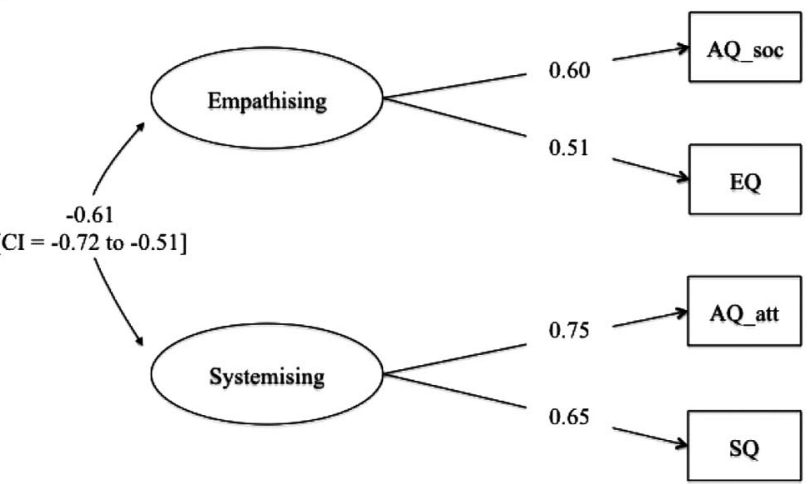

Figure 2. A, Two-factor multigroup model for the control group. B, Two-factor multigroup model for the parent group. C, Two-factor multigroup model for the ASC group. AQ_att = attention to detail factor of the Autism Quotient; AQ_soc = social interaction factor of the Autism Quotient; $\mathrm{CI}=95 \%$ confidence interval; EQ $=$ Empathy Quotient; SQ = Systemizing Quotient Revised.

use systemizing strategies in empathy tasks. For example, when an individual with ASC engages in an activity requiring empathizing, they may use systemizing strategies to work out what particular emotion or mental state is relevant to the situation and how to respond appropriately. The use of such strategies may result in an association between empathizing and systemizing, and as such when attempting to measure empathy in this group we may actu- ally be indirectly measuring the systemization of empathy. If this strategy does not improve empathizing ability, the correlation would remain strong and in a negative direction. However, if systemizing is a helpful strategy and improves empathizing ability, then it is likely to lower the negative correlation between empathizing and systemizing. Although the current study cannot identify whether such strategies are being used, our results call for further research into the types of strategies used by individuals with ASC in their approach to tasks of empathy.

Our findings suggest that there is a relatively stronger overlap between empathizing and systemizing in individuals with a high and medium genetic risk for autism compared with individuals with a low genetic risk. This overlap could be attributable to genetic and/or environmental influences. Although the design of the current study did not allow us to examine the nature of the association, we may consider possible genetic and environmental mechanisms that may underlie the different associations between empathizing and systemizing in groups of varying genetic risk for autism.

One possible explanation for the high inverse association between empathizing and systemizing in the ASC and parent group compared with the modest association found in people with no relatives with ASC could be genetic heterogeneity. The genetic risk for autism is thought to stem from a variety of different sources, including common genetic variants with relatively weak effects (Anney et al., 2010; Arking et al., 2008; Chakrabarti et al., 2009) and rare gene mutations and copy number variations (CNVs) with proportionally larger effects (Levy et al., 2011; Sebat et al., 2007). Although this is not within the scope of the current study, further investigation into whether common genetic variants may help to explain the variation in empathizing and systemizing traits in the general population is warranted. In contrast, rare CNVs and gene mutations with a relatively large effect may be more common in families affected by autism. Previous molecular genetic studies of autism show that rare $\mathrm{CNV}$ s thought to have a role in autism etiology can occur de novo (i.e., a new mutation that was not inherited from either parent; Sanders et al., 2011), but can also be transmitted from parent to child (Levy et al., 2011). Further research would benefit from assessing whether gene variants with relatively large effects impact upon both systemizing and empathizing. Such heterogeneous genetic effects, although at present speculative, could possibly explain the strong relationship between empathizing and systemizing in individuals with ASC and parents, compared with the small association observed in control samples.

Alternatively, there may be heterogeneous environmental influences on empathizing and systemizing across the three different groups. As yet little is known about possible influences of environmental effects of autism, with peri and prenatal complications one of the most consistently reported possible environmental risk factors (Kolevzon, Gross, \& Reichenberg, 2007). Future research would benefit from direct assessment of the impacts of environmental factors on both systemizing and empathizing in samples with varying degrees of genetic vulnerability for autism.

\section{Limitations}

The current study had a number of limitations. The study was restricted in that the parent group contained a larger proportion of mothers $(n=298)$ than fathers $(n=141)$, whereas the sex 
ratio was approximately equal in the other two groups. The sex effects on the mean scores of the variables were accounted for by standardizing for the effect of gender before conducting the factor analyses. Sex differences in latent structure were also explored, indicating that the factor structure obtained does not differ by sex. However, larger numbers in each group would serve to increase power for such types of comparisons. Second, the ASC sample group consisted of high functioning adults with an autism spectrum disorder. As is often the case in cognitive studies of autism (Hoekstra \& Whatson, 2010), our study design using questionnaire self-ratings precluded the participation of individuals at the lower functioning end of the spectrum. It is less straightforward to test empathizing and systemizing in individuals on the spectrum who also have intellectual disability. Nevertheless, some characteristics of low functioning autism, such as the relative talent (compared to other abilities) in solving puzzles, a great interest in lawful systems, and increased attention to small changes in the environment all hint toward a drive to systemize (Baron-Cohen et al., 2005), whereas delays and deficits in Theory of Mind development, even when compared with control children of similar mental age, suggest empathy impairments also apply to the lower functioning end of the autism spectrum (Abell, Happé, \& Frith, 2000; BaronCohen, 1995). However, whether the factor structure between empathizing and systemizing as found in high functioning individuals with autism in our study also generalizes to individuals on the spectrum with intellectual disability remains unknown.

The measures used in this study were all questionnaire based and all concerned self-report. Future research should also incorporate cognitive performance measures and second person ratings of empathizing and systemizing. Of further interest would be to examine the extent to which other behavioral or psychiatric problems commonly found to be comorbid with autism (e.g., attention problems) may moderate the association between empathizing and systemizing.

Because the study was conducted using an online volunteer register it was not possible to verify whether subjects met ASC diagnostic criteria. However, it has been reported that diagnoses in online volunteers are generally reliable (Lee et al., 2010). Furthermore, online data collection enabled the collection of data from a large number of respondents from a representative sample. The use of online research in this sample may also reduce selection bias attributable to the user friendly and noninvasive nature of the research and the difficulty that individuals on the spectrum or those parents taking care of a special needs child may have in attending a face-to-face laboratory setting. A possible drawback is that the sample may have been overrepresented by participants who feel comfortable using computers and are familiar with and interested in taking part in online research.

\section{Conclusions}

The current study assessed the latent structure of empathizing, systemizing, and autistic traits across individuals with a low, medium, and high genetic vulnerability to autism. Our results indicated that a two-factor model comprising a latent empathizing and systemizing factor provided the best fit across the three groups. The inverse relationship between both traits was substan- tial in people with high and medium genetic vulnerability, but only modest in individuals with low genetic risk for autism. We speculate that the varying strength in the association between empathizing and systemizing across groups may be explained by differences in cognitive style and by genetic and possibly environmental heterogeneity. However, further research is needed to establish the impact and causality of these associations.

\section{References}

Abell, F., Happé, F., \& Frith, U. (2000). Do triangles play tricks? Attribution of mental states to animated shapes in normal and abnormal development. Cognitive Development, 15, 1-16. doi:10.1016/S08852014(00)00014-9

Abrahams, B. S., \& Geschwind, D. H. (2008). Advances in autism genetics: On the threshold of a new neurobiology. Nature reviews genetics, 9, 341-355. doi:10.1038/nrg2346

Akaike, H. (1987). Factor analysis and AIC. Psychometrika, 52, 317-332. doi:10.1007/BF02294359

American Psychiatric Association. (2000). Diagnostic and statistical manual of mental disorders (4th ed.). Washington, DC: American Psychiatric Publishing Inc.

Anney, R., Klei, L., Pinto, D., Regan, R., Conroy, J., Magalhaes, T., \& Hallmayer, J. (2010). A genome-wide scan for common alleles affecting risk for autism. Human Molecular Genetics, 19, 4072-4082. doi 10.1093/hmg/ddq307

Arking, D. E., Cutler, D., Brune, C., Teslovich, T., West, K., Ikeda, M., \& Chakravarti, A. (2008). A common genetic variant in the neurexin superfamily member CNTNAP2 increases familial risk of autism. American Journal of Human Genetics, 82, 160-164. doi:10.1016/j.ajhg.2007 .09 .015

Baron-Cohen, S. (1995). Mindblindness: An essay on autism and theory of mind. Boston, MA: MIT Press/Bradford Books.

Baron-Cohen, S. (2002). The extreme male brain theory of autism. Trends in Cognitive Sciences, 6, 248-254. doi:10.1016/S13646613(02)01904-6

Baron-Cohen, S. (2004). The cognitive neuroscience of autism. Journal of Neurology, Neurosurgery \& Psychiatry, 75, 945-948. doi:10.1136/jnnp .2003 .018713

Baron-Cohen, S. (2010). Empathizing, systemizing and the extreme male brain theory of autism. In I. Savic (Ed.), Progress in brain research: Sex differences in the human brain, their underpinnings and implications (Vol. 186, pp.167-175). Cambridge, UK: Academic Press. doi:10.1016/ B978-0-444-53630-3.00011-7

Baron-Cohen, S., \& Hammer, J. (1997). Parents of children with Asperger syndrome: What is the cognitive phenotype? Journal of Cognitive Neuroscience, 9, 548-554. doi:10.1162/jocn.1997.9.4.548

Baron-Cohen, S., Knickmeyer, R. C., \& Belmonte, M. K. (2005). Sex differences in the brain: Implications for explaining autism. Science, 310, 819-823. doi:10.1126/science.1115455

Baron-Cohen, S., Leslie, A. M., \& Frith, U. (1985). Does the autistic child have a "theory of mind"? Cognition, 21, 37-46. doi:10.1016/00100277(85)90022-8

Baron-Cohen, S., Lombardo, M. V., Auyeung, B., Ashwin, E., Chakrabarti, B., \& Knickmeyer, R. (2011). Why are autism spectrum conditions more prevalent in males? PloS Biology, 9, doi:10.1371/journal.pbio.1001081

Baron-Cohen, S., Richler, J., Bisarya, D., Gurunathan, N., \& Wheelwright, S. (2003). The systemizing quotient: An investigation of adults with Asperger syndrome or high-functioning autism, and normal sex differences. Philosophical Transactions of the Royal Society B: Biological Sciences, 358, 361-374. doi:10.1098/rstb.2002.1206

Baron-Cohen, S., Scott, F. J., Allison, C., Williams, J., Bolton, P., Matthews, F. E., \& Brayne, C. (2009). Prevalence of autism-spectrum 
conditions: UK school-based population study. The British Journal of Psychiatry, 194, 500-509. doi:10.1192/bjp.bp.108.059345

Baron-Cohen, S., \& Wheelwright, S. (2004). The empathy quotient: An investigation of adults with Asperger syndrome or high functioning autism, and normal sex differences. Journal of Autism and Developmental Disorders, 34, 163-175.. doi:10.1023/B:JADD.0000022607 .19833 .00

Baron-Cohen, S., Wheelwright, S., \& Jolliffe, T. (1997). Is there a "language of the eyes"? Evidence from normal adults, and adults with autism or Asperger syndrome. Visual Cognition, 4, 311-331. doi:10.1080/ 713756761

Baron-Cohen, S., Wheelwright, S., Lawson, J., Griffin, R., \& Hill, J. (2002). The exact mind: Empathizing and systemizing in autism spectrum conditions. In U. Goswami (Ed.), Blackwell handbook of childhood cognitive development (pp. 491-508): Malden: Blackwell Publishing. doi:10.1002/9780470996652.ch22

Baron-Cohen, S., Wheelwright, S., Skinner, R., Martin, J., \& Clubley, E. (2001). The Autism-Spectrum Quotient (AQ): Evidence from Asperger syndrome/high-functioning autism, males and females, scientists and mathematicians. Journal of Autism and Developmental Disorders, 31, 5-17. doi:10.1023/A:1005653411471

Baron-Cohen, S., Wheelwright, S., Stone, V., \& Rutherford, M. (1999). A mathematician, a physicist and a computer scientist with Asperger syndrome: Performance on folk psychology and folk physics tests. Neurocase, 5, 475-483. doi:10.1080/13554799908402743

Bentler, P. M. (1990). Comparative fit indices in structural models. Psychological Bulletin, 107, 238-246. doi:10.1037/0033-2909.107.2.238

Bölte, S., \& Poustka, F. (2006). The broader cognitive phenotype of autism in parents: How specific is the tendency for local processing and executive dysfunction? Journal of Child Psychology and Psychiatry, 47, 639-645. doi:10.1111/j.1469-7610.2006.01603.x

Bolton, P., Macdonald, H., Pickles, A., Rios, P., Goode, S., Crowson, M., \& Rutter, M. (1994). A case-control family history study of autism. Journal of Child Psychology and Psychiatry, 35, 877-900. doi:10.1111/ j.1469-7610.1994.tb02300.x

Briskman, J., Happe, F., \& Frith, U. (2001). Exploring the cognitive phenotype of autism: Weak "central coherence" in parents and siblings of children in autism: II. Real-life skills and preferences. Journal of Child Psychology and Psychiatry, 42, 309-316. doi:10.1111/1469-7610 .00724

Brown, T. A. (2006). Confirmatory Factor Analysis for Applied Research. New York, NY: The Guildford Press.

Browne, M. W., \& Cudeck, R. (1993). Alternate ways of assessing model fit. In K. A. Bollen \& J. S. Long (Eds.), Testing Structural Equation Models (pp. 136-162). Newbury Park, CA: Sage.

Brugha, T. S., McManus, S., Bankart, J., Scott, F., Purdon, S., Smith, J., \& Meltzer, H. (2011). Epidemiology of autism spectrum disorders in adults in the community in England. Archives of General Psychiatry, 68, 459-466. doi:10.1001/archgenpsychiatry.2011.38

Chakrabarti, B., Dudbridge, F., Kent, L., Wheelwright, S., Hill-Cawthorne, G., Allison, C., \& Baron-Cohen, S. (2009). Genes related to sex steroids, neural growth, and social-emotional behavior are associated with autistic traits, empathy, and Asperger syndrome. Autism Research, 2, 157-177. doi:10.1002/aur.80

Constantino, J. N., Gruber, C. P., Davis, S., Hayes, S., Passanante, N., \& Przybeck, T. (2004). The factor structure of autistic traits. Journal of Child Psychology and Psychiatry, 45, 719-726. doi:10.1111/j.14697610.2004.00266.x

Corbett, B. A., Constantine, L. J., Hendren, R., Rocke, D., \& Ozonoff, S. (2009). Examining executive functioning in children with autism spectrum disorder, attention deficit hyperactivity disorder and typical development. Psychiatry Research, 166, 210-222. doi:10.1016/j.psychres .2008 .02 .005
Geschwind, D. H. (2011). Genetics of autism spectrum disorders. Trends in Cognitive Sciences, 15, 409-416. doi:10.1016/j.tics.2011.07.003

Goldenfeld, N., Baron-Cohen, S., \& Wheelwright, S. (2005). Empathizing and systemizing in males, females, and autism. Clinical Neuropsychiatry: Journal of Treatment Evaluation, 2, 338-345.

Goldenfeld, N., Baron-Cohen, S., Wheelwright, S., Ashwin, C., \& Chakrabarti, B. (2007). Empathizing and systemizing in males, females and autism: A test of the neural competition theory. In T. Farrow \& P. Woodruff (Eds.), Empathy in mental illness (pp. 322-334). New York, NY: Cambridge University Press. doi:10.1017/CBO9780511543753 .019

Happé, F., Briskman, J., \& Frith, U. (2001). Exploring the cognitive phenotype of autism: Weak "central coherence" in parents and siblings of children with autism: I. Experimental tests. Journal of Child Psychology and Psychiatry, 42, 299-307. doi:10.1111/1469-7610.00723

Happé, F., \& Ronald, A. (2008). The 'fractionable autism triad': A review of evidence from behavioural, genetic, cognitive and neural research Neuropsychology Review, 18, 287-304. doi:10.1007/s11065-008-9076-8

Hoekstra, R. A., Bartels, M., Cath, D. C., \& Boomsma, D. I. (2008). Factor structure, reliability and criterion validity of the Autism-Spectrum Quotient (AQ): A study in Dutch population and patient groups. Journal of Autism and Developmental Disorders, 38, 1555-1566. doi:10.1007/ s10803-008-0538-x

Hoekstra, R. A., \& Whatson, T. (2010). Chapter 5: Biological explanations. In I. Roth, C. Barson, R. A. Hoekstra, G. Pasco, \& T. Whatson (Eds.), The autism spectrum in the 21st century: Exploring psychology, biology and practice. London, UK: Jessica Kingsley Publishers.

Hu, L., \& Bentler, P. M. (1999). Cutoff criterion for fit indices in covariance structure analysis: Conventional criteria versus new alternatives. Structural Equation Modeling, 6, 1-55. doi:10.1080/ 10705519909540118

Jolliffe, T., \& Baron-Cohen, S. (1997). Are people with autism and Asperger syndrome faster than normal on the Embedded Figures Test? Journal of Child Psychology and Psychiatry, 38, 527-534. doi:10.1111/ j.1469-7610.1997.tb01539.x

Kenny, D. A., Kaniskan, B., \& McCoach, D. B. (2011). The performance of RMSEA in models with small degrees of freedom (Unpublished paper). Storrs, CT: University of Connecticut.

Kolevzon, A., Gross, R., \& Reichenberg, A. (2007). Prenatal and perinatal risk factors for autism: A review and integration of findings. Archives of Pediatrics and Adolescent Medicine, 161, 326-333. doi:10.1001/ archpedi.161.4.326

Lai, M.-C., Lombardo, M. V., Pasco, G., Ruigrok, A. N. V., Wheelwright, S. J., Sadek, S. A., \& Baron-Cohen, S. (2011). A behavioral comparison of male and female adults with high functioning autism spectrum conditions. PLoS ONE, 6, e20835. doi:10.1371/journal.pone.0020835

Lawson, J., Baron-Cohen, S., \& Wheelwright, S. (2004). Empathising and systemising in adults with and without Asperger syndrome. Journal of Autism and Developmental Disorders, 34, 301-310. doi:10.1023/B: JADD.0000029552.42724.1b

Lee, H., Marvin, A. R., Watson, T., Piggot, J., Law, J. K., Law, P. A., \& Nelson, S. F. (2010). Accuracy of phenotyping of autistic children based on internet implemented parent report. American Journal of Medical Genetics, Part B: Neuropsychiatric Genetics, 153, 1119-1126.

Levy, D., Ronemus, M., Yamrom, B., Lee, Y.-H., Leotta, A., Kendall, J., \& Wigler, M. (2011). Rare de novo and transmitted copy-number variation in autistic spectrum disorders. Neuron, 70, 886-897. doi: 10.1016/j.neuron.2011.05.015

Losh, M., Adolphs, R., Poe, M. D., Couture, S., Penn, D., Baranek, G. T., \& Piven, J. (2009). Neuropsychological profile of autism and the broad autism phenotype. Archives of General Psychiatry, 66, 518-526. doi 10.1001/archgenpsychiatry.2009.34

Losh, M., \& Piven, J. (2007). Social-cognition and the broad autism phenotype: Identifying genetically meaningful phenotypes. Journal of 
Child Psychology and Psychiatry, 48, 105-112. doi:10.1111/j.14697610.2006.01594.x

Mandy, W. P. L., \& Skuse, D. (2008). Research review: What is the association between social-communication element of autism and repetitive interests, behaviours and activities. Journal of Child Psychology and Psychiatry, 49, 795-808. doi:10.1111/j.1469-7610.2008.01911.x

Muthén, L. K., \& Muthén, B. O. (2010a). Mplus. Los Angeles, CA: Muthén \& Muthén.

Muthén, L. K., \& Muthén, B. O. (2010b). Mplus User's Guide. Los Angeles, CA: Muthén \& Muthén.

Nadig, A. S., Ozonoff, S., Young, G. S., Rozga, A., Sigman, M., \& Rogers, S. J. (2007). A prospective study of response to name in infants at risk for autism. Archives of Pediatrics and Adolescent Medicine, 161, 378383. doi:10.1001/archpedi.161.4.378

Ozonoff, S., Pennington, B. F., \& Rogers, S. J. (1991). Executive function deficits in high-functioning autistic individuals: Relationship to theory of mind. Journal of Child Psychology and Psychiatry, 32, 1081-1105. doi:10.1111/j.1469-7610.1991.tb00351.x

Ozonoff, S., Young, G. S., Carter, A., Messinger, D. S., Yirmiya, N., Zwaigenbaum, L., \& Stone, W. L. (2011). Recurrence risk for autism spectrum disorders: A baby siblings research consortium study. Pediatrics, 128, e488-e495.

Piven, J., Palma, P., Landa, R., Santangelo, S., Jacobi, D., \& Childress, D. (1997). Personality and language characteristics in parents from multiple incidence autism families. American Journal of Medical Genetics (Neuropsychiatric Genetics), 74, 398-411. doi:10.1002/(SICI)10968628(19970725)74:4<398::AID-AJMG11>3.0.CO;2-D

Piven, J., Palmer, P., Jacobi, D., Childress, D., \& Arndt, S. (1997). Broader autism phenotype: Evidence from a family history study of multipleincidence autism families. The American Journal of Psychiatry, 154, 185-190.

Ronald, A. (2006). Quantitative genetic study of autistic-like traits in middle childhood: Evidence from a population twin sample for genetic heterogeneity between the behaviours that characterise autism spectrum conditions. London, UK: University of London.

Ronald, A., Happé, F., Bolton, P., Butcher, L. M., Price, T. S., Wheelwright, S., \& Plomin, R. (2006). Genetic heterogeneity between the three components of the autism spectrum: A twin study. Journal of the American Academy of Child \& Adolescent Psychiatry, 45, 691-699. doi:10.1097/01.chi.0000215325.13058.9d

Ronald, A., Happé, F., \& Plomin, R. (2005). The genetic relationship between individual differences in social and nonsocial behaviours characteristic of autism. Developmental Science, 8, 444-458. doi:10.1111/ j.1467-7687.2005.00433.x

Ronald, A., Happé, F., Price, T. S., Baron-Cohen, S., \& Plomin, R. (2006). Phenotypic and genetic overlap between autistic traits at the extremes of the general population. Journal of the American Academy of Child \& Adolescent Psychiatry, 45, 1206-1214. doi:10.1097/01.chi.0000230165 .54117 .41

Ronald, A., \& Hoekstra, R. A. (2011). Autism spectrum disorders and autistic traits: A decade of new twin studies. American Journal of Medical Genetics, Part B: Neuropsychiatric Genetics, 156, 255-274. doi:10.1002/ajmg.b.31159

Ruser, T. F., Arin, D., Dowd, M., Putnam, S., Winklosky, B., RosenSheidley, B., \& Folstein, S. (2007). Communicative competence in parents of children with autism and parents of children with specific language impairment. Journal of Autism and Developmental Disorders, 37, 1323-1336. doi:10.1007/s10803-006-0274-z

Russell, J. (1997). Autism as an executive disorder. New York, NY: Oxford University Press.

Sanders, S. J., Ercan-Sencicek, A. G., Hus, V., Luo, R., Murtha, M. T., Moreno-De-Luca, D., \& State, M. W. (2011). Multiple recurrent de novo CNVs, including duplications of the 7q11.23 Williams Syndrome region, are strongly associated with autism. Neuron, 70, 863-885. doi: 10.1016/j.neuron.2011.05.002

Savalei, V. (2010). The relationship between RMSEA and model misspecification in CFA models. Vancouver, BC: University of British Columbia.

Scheeren, A. M., \& Stauder, J. E. A. (2008). Broader autism phenotype in parents of autistic children: Reality or myth? Journal of Autism and Developmental Disorders, 38, 276-287. doi:10.1007/s10803-0070389-x

Schwarz, G. (1978). Estimating the dimension of a model. Annals of Statistics, 6, 461-464. doi:10.1214/aos/1176344136

Sclove, S. L. (1987). Application of model-selection criteria to some problems in multivariate-analysis. Psychometrika, 52, 333-343. doi: 10.1007/BF02294360

Sebat, J., Lakshmi, B., Malhotra, D., Troge, J., Lese-Martin, C., Walsh, T., \& Wigler, M. (2007). Strong association of de novo copy number mutations with autism. Science, 316, 445-449. doi:10.1126/science .1138659

Steiger, J. H., \& Lind, J. M. (1980). Statistically based tests for the number of common factors. Paper presented at the meeting of the Psychometric Society, Iowa City, IA.

Sucksmith, E., Allison, C., Baron-Cohen, S., Chakrabarti, B., \& Hoekstra R. (2013). Empathy and emotion recognition in people with autism, first-degree relatives and controls. Neuropsychologica, 51, 98-105.

Sucksmith, E., Roth, I., \& Hoekstra, R. A. (2011). Autistic traits below the clinical threshold: Re-examining the Broader Autism Phenotype in the 21st century. Neuropsychology Review, 21, 360-389. doi:10.1007/ s11065-011-9183-9

Toth, K., Dawson, G., Meltzoff, A. N., Greenson, J., \& Fein, D. (2007). Early social, imitation, play, and language abilities of young non-autistic siblings of children with autism. Journal of Autism and Developmental Disorders, 37, 145-157. doi:10.1007/s10803-006-0336-2

Tucker, L. R., \& Lewis, C. (1973). A reliability coefficient for maximum likelihood factor analysis. Psychometrika, 15, 149-162.

Wheelwright, S., Baron-Cohen, S., Goldenfeld, N., Delaney, J., Fine, D., Smith, R., \& Wakabayashi, A (2006). Predicting Autism Spectrum Quotient (AQ) from the Systemizing Quotient-Revised (SQ-R) and Empathy Quotient (EQ). Brain Research, 1079, 47-56. doi:10.1016/j brainres.2006.01.012

White, S. J., \& Saldaña, D. (2011). Performance of children with autism on the Embedded Figures Test: A closer look at a popular task. Journal of Autism and Developmental Disorders, 41, 1565-1572. doi:10.1007/ s10803-011-1182-4

Received May 25, 2012

Revision received December 13, 2012 Accepted December 13, 2012 